\title{
Mural paintings deterioration - a multianalytical approach
}

Rosado, T. ${ }^{* * *}$, Mirão, J. ${ }^{* * * *}$, Candeias, A., ${ }^{* * *}$ and Caldeira, A.T. ${ }^{* * * *}$

*HERCULES Laboratory, Évora University, Largo Marquês de Marialva 8, 7000-809 Évora, PORTUGAL *Évora Chemistry Centre and Chemistry Department, Évora University, Rua Romão Ramalho 59, $7000-671$ Évora, PORTUGAL

***Évora Geophysics Centre and Geosciences Department, Évora University, Rua Romão Ramalho 59, 7000671 Évora, PORTUGAL

Email: $\underline{\text { atc@uevora.pt }}$

Historical built heritage, like mural paintings, are important landmarks that play an important role on the sustainable development of a region or country and therefore its degradation is a problem with social and economic impact. Its degradation depends on the physical properties and chemical nature of the substrate as well as extrinsic factors including biological attack and several environmental parameters like humidity, temperature, $\mathrm{pH}$ and light [1].

This work presents a novel microanalytical approach in the mural paintings microbial diversity characterisation and identification of the damages promoted by their biological activity.

Mortar microfragments, removed from visually biodegraded mural paintings, were analysed by several microscopic/spectroscopy techniques: variable pressure scanning electron microscopy coupled with energy dispersive X-ray spectrometry (VP-SEM-EDS), raman microspectrometry and infrared spectrometry in order to evaluate the presence of microbial contamination and to detect the alteration products resulting from the metabolic activity of the microorganisms [2]. These analyses were complemented with culture-dependent methods and DNA based approaches, like DGGE and pyrosequencing [3,4], aiming the identification of the biota involved in the biodeterioration phenomena.

Samples collected with sterile cotton swabs were used for microbiological assays and then inoculated in selective culture media, in order to identify the microorganisms that are able to grow in laboratorial conditions. The identification of the microbial isolates was performed based on the macroscopic and microscopic features. Metagenomic DNA extracted from microfragments of mortar were also analysed by DGGE and by pyrosequencing, an innovative molecular assessment, which allows the identification of a significant number of microorganisms.

SEM analyses of mortar microfragments (Fig. 1A,B) allowed the observation of the microbial communities thriving in the paintings. Fungal hyphae and micellar structures of filamentous fungi penetrate in the microstructure of the mortars promoting the appearance of cracks, detachments and biofilms in the paintings. The presence of microbial contamination was confirmed through the spectra profile obtained by Raman microscopy, nevertheless this technique was also crucial in the detection of alteration products, like calcium oxalates (Fig. 2A) and carotenoids (Fig. 2B), resulting from the metabolic activity of the microorganisms.

Pyrosequencing and DGGE, were important tools in the detection of microbial communities present in the samples giving a more detailed panorama of its biodiversity.

These results will be useful in the future, to build up a global inventory of the biological agents that can be associated with the biodegradation of wall paintings and to plan effective remediation strategies.

Tânia Rosado acknowledges Fundação para a Ciência e Tecnologia for financial support (PhD grant,FRH/BD/65747/2009) through program QREN-POPH-typology 4.1., co-participated by the Social European Fund (FSE) and MCTES National Fund. 
[1] Sterflinger, K., Fungal Biology Reviews, 24, 47-55, 2010.

[2] Perez-Alonso, M. et al., Analytical and Bioanalytical Chemistry, 379, 42-50, 2004.

[3] J.M. Gonzalez et al., Journal of Separation Science, 27, 174-180, 2004.

[4] Ronaghi, M., Genome Research, 11, 3-11, 2001.

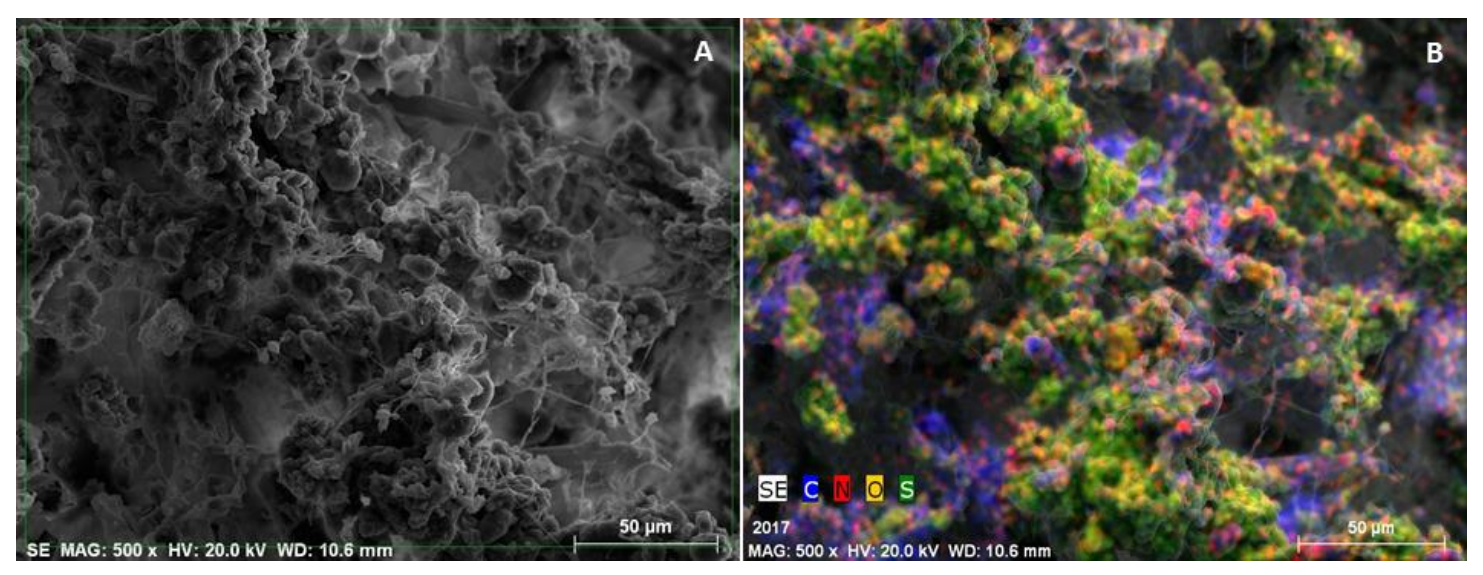

Figure 1. A) SEM micrograph of mortar microfragment showing microbial contamination, B) SEM-EDS analysis presenting organic compounds.
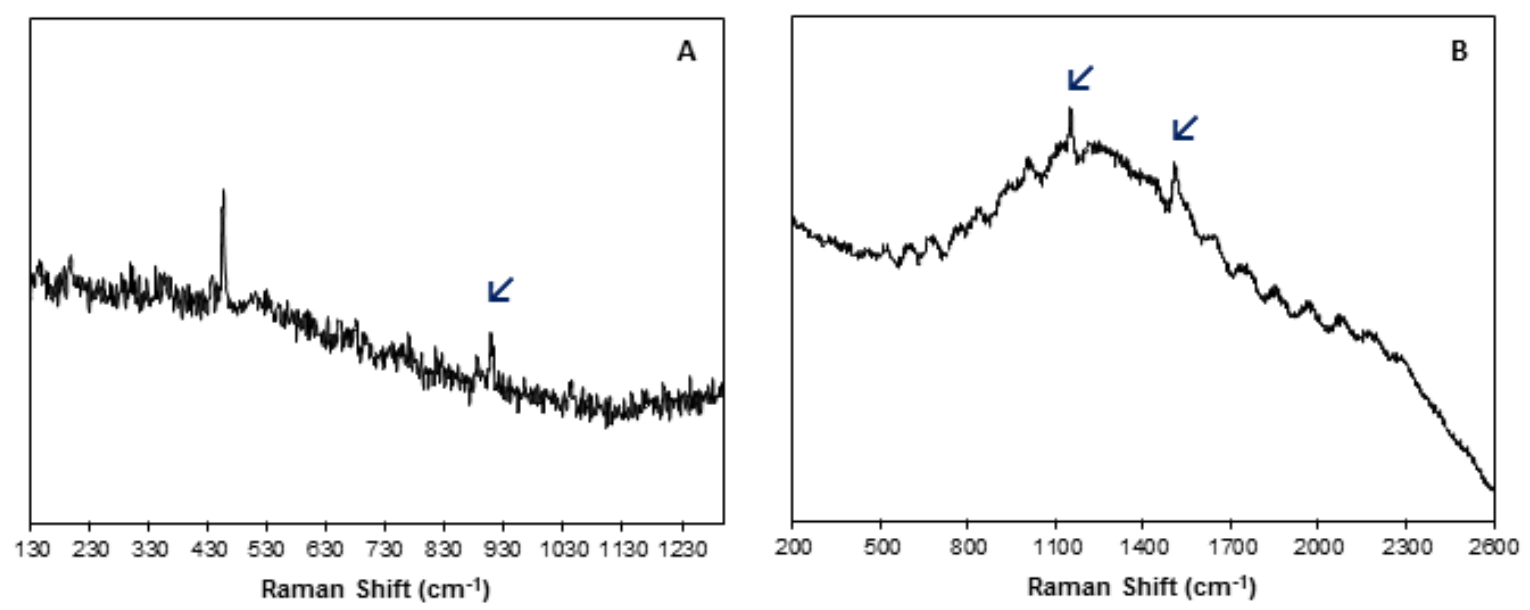

Figure 2. Calcium oxalates (A) and carotenoids (B) detection in mortar microfragments by Raman analysis. 